Original Research Paper

\title{
Hydraulic Flow through Engineering Bentonite-Based Containment Barriers
}

\author{
${ }^{1}$ Eric Wooi Kee Loh and ${ }^{2}$ Devapriya Chitral Wijeyesekera \\ ${ }^{1}$ Faculty of Science, Technology, Engineering and Mathematics, INTI International University, Negeri Sembilan, Malaysia \\ ${ }^{2}$ Faculty of Civil and Environmental Engineering, Universiti Tun Hussein Onn Malaysia, Johor, Malaysia
}

\author{
Article history \\ Received: 10-08-2015 \\ Revised: 02-11-2015 \\ Accepted: 3-11-2015 \\ Corresponding Author: \\ Eric Wooi Kee Loh \\ Faculty of Science, \\ Technology, Engineering and \\ Mathematics, INTI \\ International University, Negeri \\ Sembilan, Malaysia \\ Email: ericdrloh@gmail.com.my
}

\begin{abstract}
This paper presents the use of software modelling as a tool to study the impact of hydraulic "resistivity" on the contaminant transport through bentonite-based containment barriers. A sensitivity analysis on the predicted data was carried out by varying the boundary conditions as well as the hydraulic resistance to flow through varying contaminant transport parameters. Accordingly, both advective and diffusive flow processes are considered as that which resists the flow. In particular, the effect on the contaminant migration due to desiccation cracking is explored. Laboratory evidence is provided and discussed to show how the initial microstructure of the clay influences the development of subsequent macro structural features such as shrinkage crack patterns. The effect of these cracks and the intensity of cracking on the contaminant migration are modelled and pragmatically discussed. Additionally, the effect on the hydraulic conductivity of bentonite-based barriers, when permeated with non-standard liquids is discussed and a typical analytical output is presented.
\end{abstract}

Keywords: Bentonite, Containment Barriers, Leachate, Cation Exchange, Advective and Diffusive Flow

\section{Introduction}

Barriers built with natural and synthetic materials have been widely used in Geo-environmental Engineering to retard contaminant migration. Amongst others, clay is popularly used as engineered barriers or as an essential component in most synthetic landfill liners to minimise migration of contaminants or for water proofing structures. Waste disposal sites need to adhere to stringent regulations on the disposal of municipal, industrial and hazardous wastes. EU directives recommend low permeability soils, which naturally should contain bentonite, as a sealing material in the construction and rehabilitation of landfills to ensure the protection of groundwater from pollutants. Such clay barriers vary from thin Geosynthetic Clay Liners (GCL; 4.5 to $9 \mathrm{~mm}$ thick), to Compacted Clay Liners, (CCL; 0.6 to $2 \mathrm{~m}$ thick) to naturally undisturbed clayey barriers up to 30 or $40 \mathrm{~m}$ thick.

A full definition of CCL is found in the Landfill Directive; whereas, GCLs are commonly known as factory-manufactured contaminant barriers that consist of a thin layer of either calcium or sodium bentonite core sandwiched between two geotextiles. They are a popular alternative used in waste-containment facilities than CCLs due to their low hydraulic conductivity, ease of installation and perceived resistance to environmental distress (Koerner, 1997). The primary differences between them are the mineralogy and form of bentonite (e.g., powder/granular versus pre-hydrated and extruded with plasticine consistency; sodium versus calcium adsorbed ion, Cation exchange capacity) used in the core of GCL, the type of geotextile (e.g., woven versus nonwoven); or the addition of a geomembrane and the bonding methods (e.g., adhesive bonding, stitch bonding or needle punching).

The hydraulic conductivity of bentonite and clay soil in general, depends on the fraction of free water and the size as well as the tortuosity of the pathways through which the free water flows. A change in the fraction of the pore space filled with bound water results in a corresponding change in fraction of the pore space filled with free water, as well as changes in the flow paths. Thus, factors that affect the fraction of bound water directly affect the hydraulic conductivity of bentonite (Wijeyesekera et al., 2012; Shackelford et al., 2000; Mesri and Olsen, 1971; McNeal et al., 1966). Various 
studies have shown that the hydraulic conductivity of GCLs can be affected between a factor of 10 and 10,000 when permeated with inorganic permeant solutions (Liu et al., 2015; Scalia et al., 2014; Shackelford et al., 2014; 2000; Hosney and Rowe, 2013; Mazzieri et al., 2013; Zhu et al., 2013; Benson et al., 2010; Brown and Shackelford, 2007; Katsumi et al., 2007; Jo et al., 2004; 2001; Lee and Shackelford, 2005; Guyonnet et al., 2005; Kolstad et al., 2004; Egloffstein, 2001; Jo et al., 2001; Petrov and Rowe, 1997).

\section{Hydraulic Performance Modelling}

The theory and governing equations of flow and transport in porous media has been the subject of extensive research, particularly in the past two decades, in response to problems arising from subsurface contamination (Mategaonkar and Eldho, 2012; Cortazar and Monzon, 2007; El-Fadel et al., 1997; US EPA, 1993). Analytical or numerical models have been developed to simulate subsurface leachate flow and transport. Though all these models solve mass, momentum and heat transport equations, the individual model capabilities and solution schemes can differ widely. Inclusion of the detailed discussion on these is beyond the scope of this paper. The four different processes of contaminant migration are:

- Advection; the movement of the contaminant with the seepage of the groundwater

- Dispersion; the apparent mixing and spreading of the contaminant within the flow system

- Adsorption; the process by which chemical dissolved in the groundwater clings to a solid surface which decreasing the concentration of the solute

- Degradation or known as radioactive decay, which will reduce the concentration of radionuclide in both the dissolved and sorbed phases

The cumulative one dimensional effect of these contaminant processes is expressed in the following partial differential equation:

$$
D_{x} \frac{\partial^{2} c}{\partial x^{2}}-\bar{v}_{x} \frac{\partial c}{\partial x}-\lambda_{1} c-\frac{\lambda_{2} \rho_{d} c^{*}}{\theta}-R=\frac{\partial c}{\partial t}
$$

Where:

$$
\begin{aligned}
& D_{x}=\text { Hydrodynamic dispersion in } \mathrm{x}\left(\mathrm{L}^{2} \mathrm{~T}\right) \\
& \bar{v}_{x}=\text { Average linear velocity in } \mathrm{x}\left(\mathrm{L}^{2} \mathrm{~T}^{-1}\right) \\
& \lambda_{1}=\text { Dissolved half-life }\left(\mathrm{T}^{-1}\right) \\
& \lambda_{2}=\text { Sorbed half-life }\left(\mathrm{T}^{-1}\right) \\
& c=\text { Dissolved concentration }\left(\mathrm{L}^{3} \mathrm{M}^{-1}\right) \\
& c^{*}=\text { Sorbed concentration }\left(\mathrm{ML}^{-3}\right) \\
& \rho_{d}=\text { Bulk density }\left(\mathrm{ML}^{-3}\right)
\end{aligned}
$$

$$
\begin{aligned}
& \theta=\text { Volumetric water content }(-) \\
& R=\text { Retardation factor of soption isotherm (-) }
\end{aligned}
$$

This can be extended to the case of two and threedimensions by simply adding the corresponding terms for hydrodynamic dispersion and advection in the $y$ and $\mathrm{z}$ direction.

\section{Case 1: Qualitative Comparison of Barriers Performance}

Two identical Compacted Clay (CC) barriers of different hydraulic conductivity were used to representing the defection due to poor construction. Polymerised Bentonite (PB) barriers of difference thickness were used to demonstrate the distinction of single and double layer. These are underlain by a hypothetical $5 \mathrm{~m}$ thick geological layer overlying an aquifer. Vertical advective flow seepage results from a leachate head of $0.3 \mathrm{~m}$. Other relevant input information is also given in Table 1. The model considers a steady state condition with constant influent flux. An aqueous phase effective diffusion coefficients, $D^{*}$ of $1 \times 10^{-9} \mathrm{~m}^{2} / \mathrm{s}$ was adopted (Bourg et al., 2007; García-Gutiérrez et al., 2004; Shackelford and Daniel, 1991a; 1991b; Iversen and Jorgensen, 1993). The advective and diffusive equivalency was then investigated separately.

Figure 1 shows an output that result from a purely advective contaminant transport analysis. The result demonstrates the advantage from using a thin layer of PB in terms of preventing advective transport. The completion of the break through took 4.8 years in the case of a single layer of $\mathrm{PB}_{1}(5 \mathrm{~mm})$ and 10.8 years for the case of a double layer of $\mathrm{PB}_{2}(10 \mathrm{~mm})$. In comparison with the $\mathrm{CC}_{1}$ (poorly constructed) and $\mathrm{CC}_{2}$ (favourably constructed), the break through time have been reduced to 1.5 and 4.2 years respectively.

Although the thin layer of PB gave desirable results in term of hydraulic conductivity, the break through time of PB (10 mm in thickness) was not comparable to the $\mathrm{CC}$ (1000 $\mathrm{mm}$ in thickness) in term of the advectivedispersive contaminant transport as evidenced in Figure 2. Nonetheless, the PB generally exhibits a higher adsorption capacity; but, is not enough to compensate the lack of diffusive equivalency in short term. Looking at the long term performance of these two distinct barriers; the primary concern is the relative concentration for the contaminant versus time at the exit boundary is much higher when a CC is used.

\section{Case 2: Cracking Effect of the Bentonite-Based Barriers}

Drying process that occurs when bentonite clay barriers are isolated from groundwater is the commonly known mechanism for the engineered clay in the liner to crack during desiccation. 
Eric Wooi Kee Loh and Devapriya Chitral Wijeyesekera / American Journal of Applied Sciences 2015, 12 (11): 785.793 DOI: 10.3844/ajassp.2015.785.793

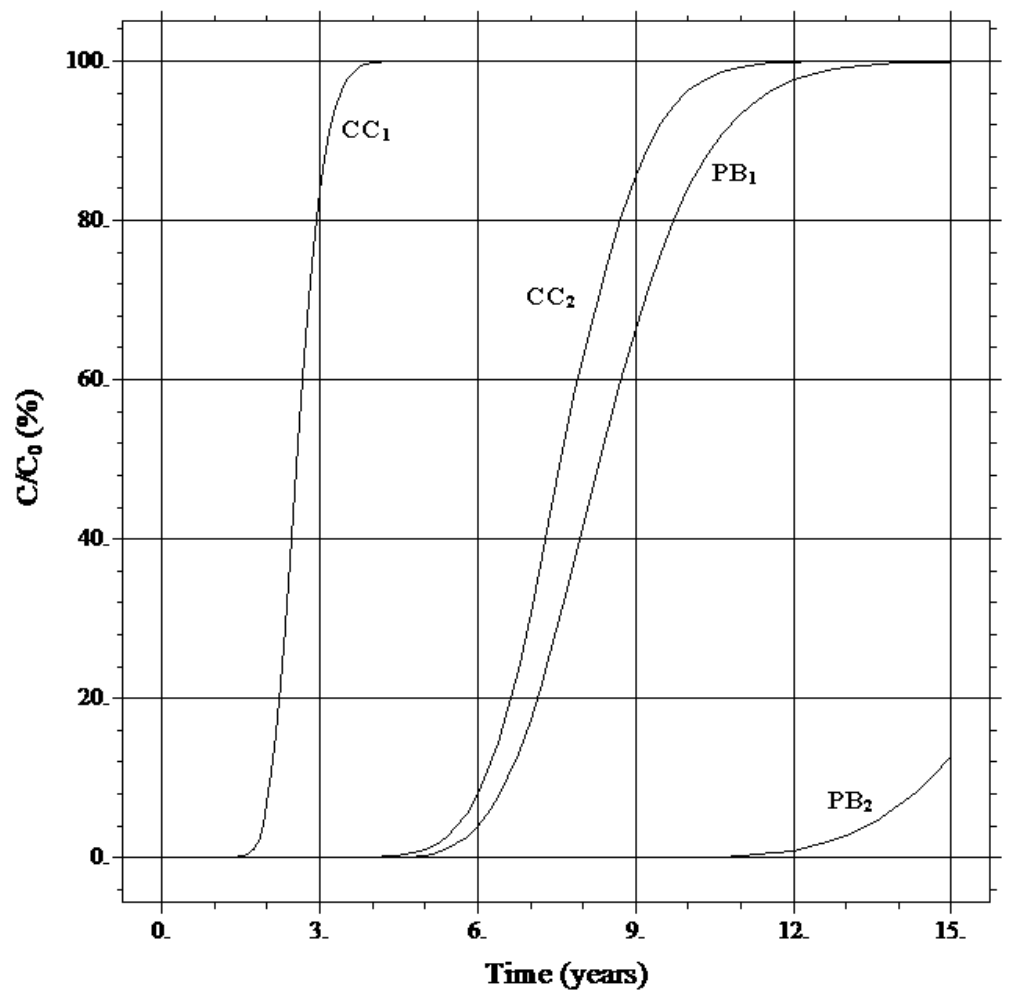

Fig. 1. Purely advective contaminant transport

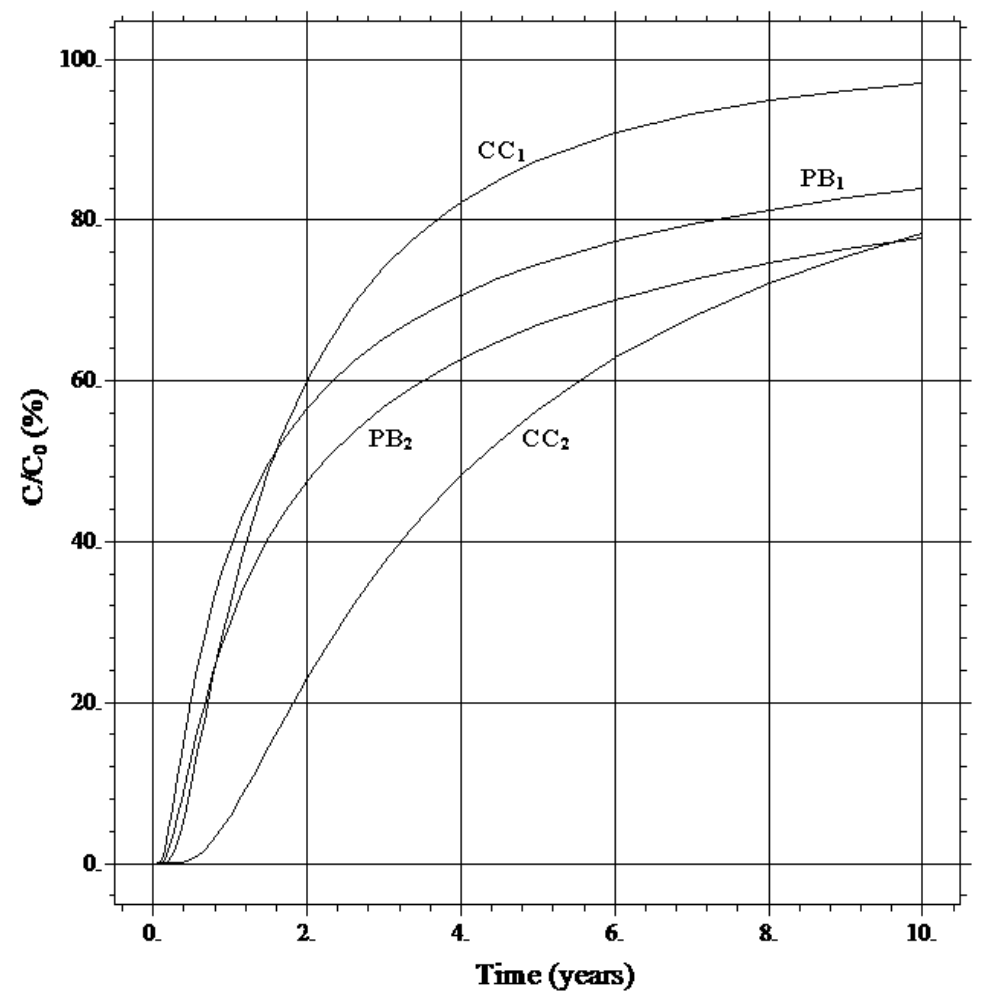

Fig. 2. Advective-dispersive contaminant transports 
Table 1. Input parameters and analysis results for model of $\mathrm{CC}$ and $\mathrm{PB}$ performance

\begin{tabular}{lllll}
\hline Parameter & $\mathrm{CC}_{1}$ & $\mathrm{CC}_{2}$ & $\mathrm{~PB}_{1}$ & $\mathrm{~PB}_{2}$ \\
\hline Thickness $(\mathrm{mm})$ & 1000 & 1000 & 5 & 10 \\
Saturated hydraulic conductivity, $\mathrm{k}_{\text {sat }}(\mathrm{m} / \mathrm{s})$ & $1 \times 10^{-7}$ & $1 \times 10^{-9}$ & $1 \times 10^{-12}$ & $1 \times 10^{-12}$ \\
Diffusion coefficient, $\mathrm{D}^{*}\left(\mathrm{~m}^{2} / \mathrm{s}\right)$ & $1 \times 10^{-9}$ & $1 \times 10^{-9}$ & $1 \times 10^{-9}$ & $1 \times 10^{-9}$ \\
Longitudinal dispersivity, $\alpha_{\mathrm{L}}\left(\mathrm{m}^{2} /\right.$ years) & 0.6 & 0.6 & 0.6 & 0.6 \\
Transverse dispersivity, $\alpha_{\mathrm{T}}\left(\mathrm{m}^{2} /\right.$ years) & 0.06 & 0.06 & 0.06 & 0.06 \\
Leachate head $(\mathrm{m})$ & 0.3 & 0.3 & 0.3 & 0.3 \\
Leachate source strength, $\mathrm{C}_{0}\left(\mathrm{mg} / \mathrm{m}^{3}\right)$ & 100 & 100 & 100 & 100 \\
Case A: Advective Only & & 4.2 & 4.8 & 10.8 \\
Break through Time (years) & 1.5 & 7.3 & 8.2 & $>>15$ \\
Time for 50\% of concentration (years) & 2.5 & & 20 & 29 \\
Case B: Advective-dispersive & & 68 & & 2.5 \\
Break through Time (days) & 35 & 4.2 & & 2.2 \\
Time for 50\% of concentration (years) & 1.5 & & & \\
\hline
\end{tabular}

Table 2. Input parameters and analysis results for cracking effect

\begin{tabular}{|c|c|c|c|c|c|c|}
\hline Cracks parameter & A & $\mathrm{B}$ & $\mathrm{C}$ & $\mathrm{D}$ & $\mathrm{E}$ & $\mathrm{F}$ \\
\hline Number of cracks, $\mathrm{N}$ & 0.00 & 1.0 & 2.0 & 4.00 & 8.000 & 20.00 \\
\hline Width, a (m) & -0.00 & 0.2 & 0.1 & 0.05 & 0.025 & 0.01 \\
\hline Spacing, $\mathrm{n}(\mathrm{m})$ & -0.00 & 0.8 & 0.4 & 0.20 & 0.100 & 0.04 \\
\hline Break through Time (days) & 2.80 & 2.3 & 1.4 & 1.60 & 1.600 & 1.80 \\
\hline Arriving Time for $50 \%$ of concentration (days) & 110.00 & 75.0 & 60.0 & 60.00 & 60.000 & 60.00 \\
\hline
\end{tabular}

Freeze thaw effects in the clay, moisture loss due to vapor transpiration from air spaces created by wrinkling of the geomembrane promote the occurrence of cracking. These allow the collection of the evaporated moisture from the underlying clay barriers, causing them to later condense and fall by gravity away from the original source due to diurnal temperature changes. In addition to above, particular attention must also be given to cracking that occur due to the cation exchange within bentonite which normally occurs over a period of approximately 13 years (Bradshaw et al., 2013; Benson and Meer, 2009; Wijeyesekera, 2003; Egglofstein, 1997).

The bentonite in the linear system generally is found either as air dried granulated/powdered or as prehydrated and extruded form. The loss of its function as a barrier in dry system due to desiccation cracking are incessantly reported by numerous people (He et al., 2015; Rowe and Verge, 2013; Wijeyesekera et al., 2012; Scalia and Benson, 2011; Egloffstein, 2001; Hewitt and Philip, 1999). A non-uniform distribution of granulated bentonite accentuates the formation of crack patterns.

This is readily recognized to occur in the dry bentonite system. The intensity of cracking varies with the thickness (mass/unit area) as observed by (Wijeyesekera et al., 2012). Figure 3 illustrates this observation.

When the dry bentonite adsorbs water for swelling, plastification can occur close to the desiccation cracks. This occurrence is conceivable. Accordingly an increased water flow can occur through the bentonite barries, depending on the extent of the cracking (intensity; spacing, width and length of cracks) and the hydraulic gradient. The geometry and in particular, the width of the cracks in the bentonite layer are decisively dictated by the kind of encapsulation of the bentonite between the cover and a carrier geotextile.

The parameter used in this model simulation are rather conservative, the bentonite barries is assume to have total $20 \%$ of volumetric shrinkage and the hydraulic conductivity of the desiccation crack was set to $1 \times 10^{-5} \mathrm{~m} / \mathrm{s}$. A crack index as shown below was used to help quantify the cracking in the modeling domain and the modeling domain was tabulated in Table 2:

$$
S \%=\frac{N a}{L}
$$

Where:

$$
\begin{aligned}
& S \%=\text { Shrinkage in percentage } \\
& N=\text { Number of cracks } \\
& a=\text { Width of cracks } \\
& L=1 \mathrm{~m}
\end{aligned}
$$

Figure 4 indicated that with cracks, the potential contamination is confined to a time period of a few years; however it will decreases as the intensity of desiccation cracks increases. The higher flow velocities in the fracture cause more rapid and higher concentration of contaminant transport in that region.

Figure 5 depicts the long term effect of increasing the intensity of crack. What is most interesting to note in the graph is that, contaminant migration is susceptible to the intensity of cracking rather than its width. The bentonite barrier are generally very thin; for long term, while higher groundwater velocities within the crack increase the speed of the plume spread, they increase dilution ratio and hence tend to decrease the concentration. 


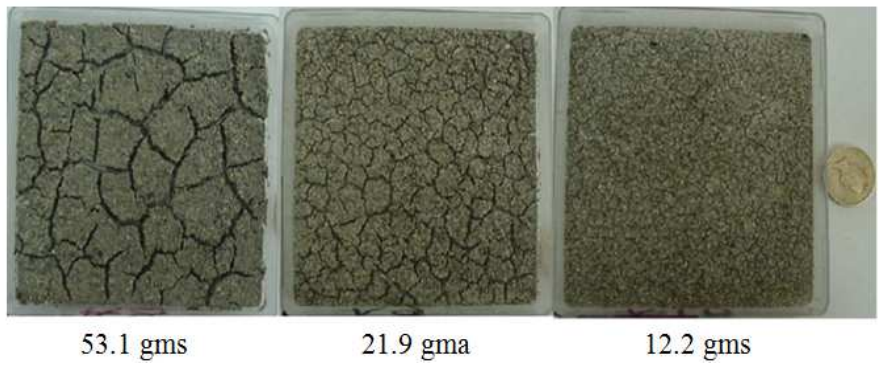

Fig. 3. Desiccation crack patterns-the effect of thinning out of the dry bentonite (Wijeyesekera et al., 2012)

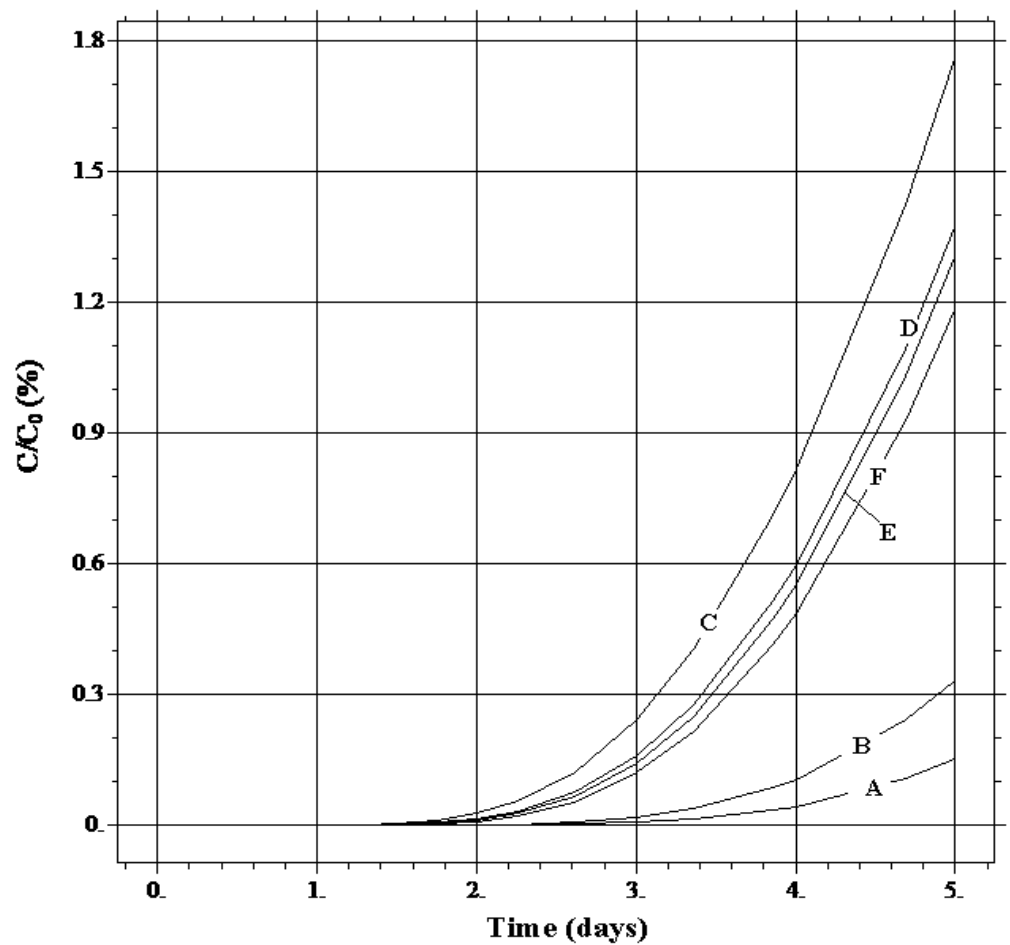

Fig. 4. Short-term effect of different cracking scenario

\section{Case 3: Performance of Bentonite Barrier under} Hostile Geo-Chemical Environment

Bentonite barriers are often used to contain liquids other than water and, thus, there has been considerable interest in modelling the performance of system in aqueous permeant solution. Prehydration has been suggested as a means to prevent the hydraulic conductivity of bentonite barriers from being altered by leachate permeation. Prehydration is hydration of the bentonite with a dilute solution (e.g., deionized, distilled, or tap water) by soaking or permeation prior to permeation by a chemical solution (Liu et al., 2015; Scalia et al., 2014; Shackelford et al., 2014; 2000; Mazzieri et al., 2013; Zhu et al., 2013; Brown and Shackelford, 2007; Katsumi et al., 2007; Jo et al., 2004; 2001; Kolstad et al., 2004; Egloffstein, 2001; Vasko et al., 2001; Petrov and Rowe, 1997; Ruhl and Daniel, 1997).
In the author's point of view, prehydration in the field may occur naturally due to migration of water from an underlying subgrade (as a result of capillary effects or vapor-phase diffusion) or may be effected intentionally (e.g., spraying or inundating the bentonite barriers); however, the optimal prehydration state will not always accomplished. Therefore; the focus of this section is on the applications of bentonite barrier when subjected to complex aqueous permeant solution and complete prehydration by permeation with distilled, deionized, or potable water is unlikely to be achieved at site. To facilitate this modelling, long-term hydraulic conductivity of a bentonite permeated with inorganic salt solutions and the diffusion coefficients for inorganic molecules was adopted from (Jo et al., 2004; Shackelford and Daniel, 1991a; 1991b) respectively. Other relevant input information is also given in Table 3. 
Eric Wooi Kee Loh and Devapriya Chitral Wijeyesekera / American Journal of Applied Sciences 2015, 12 (11): 785.793 DOI: 10.3844/ajassp.2015.785.793

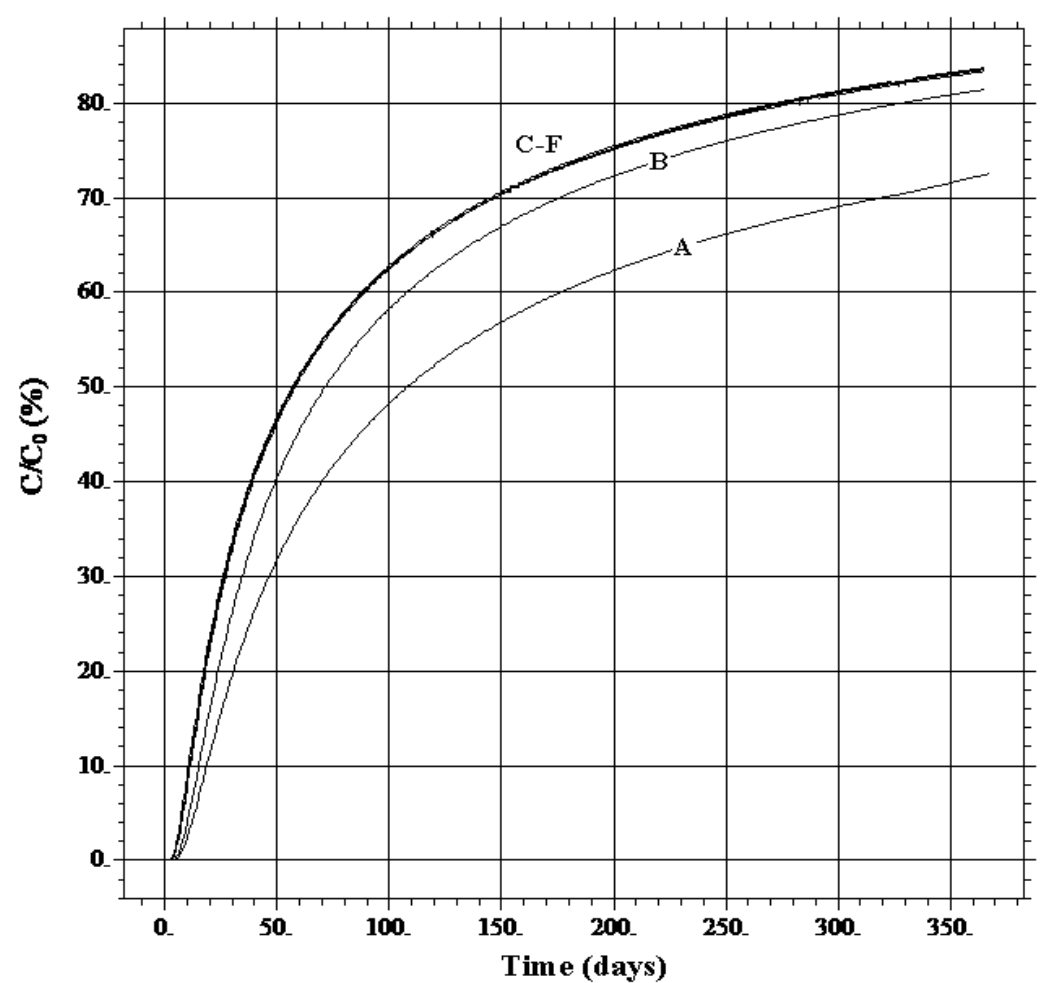

Fig. 5. Long-term effect of different cracking scenario

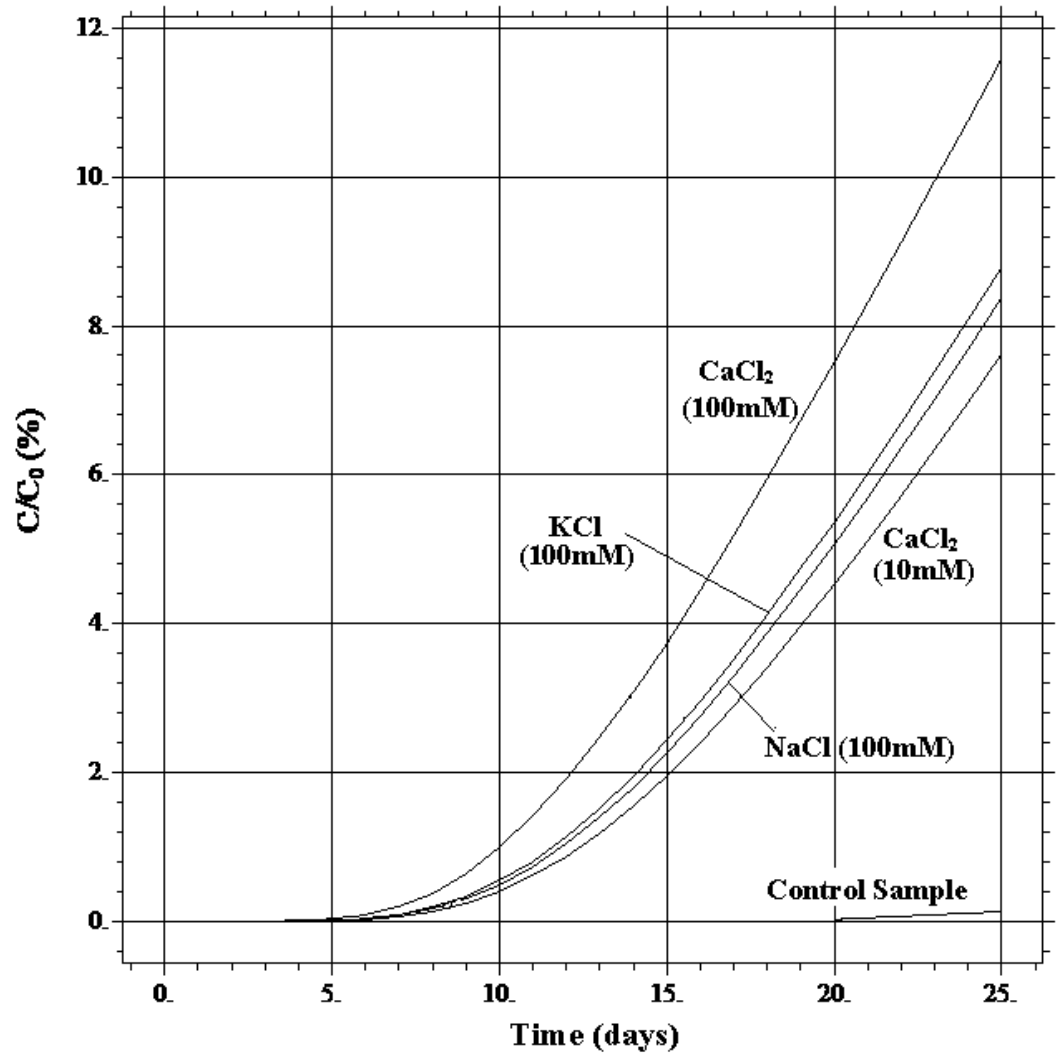

Fig. 6. Short-term effect of different permeant 


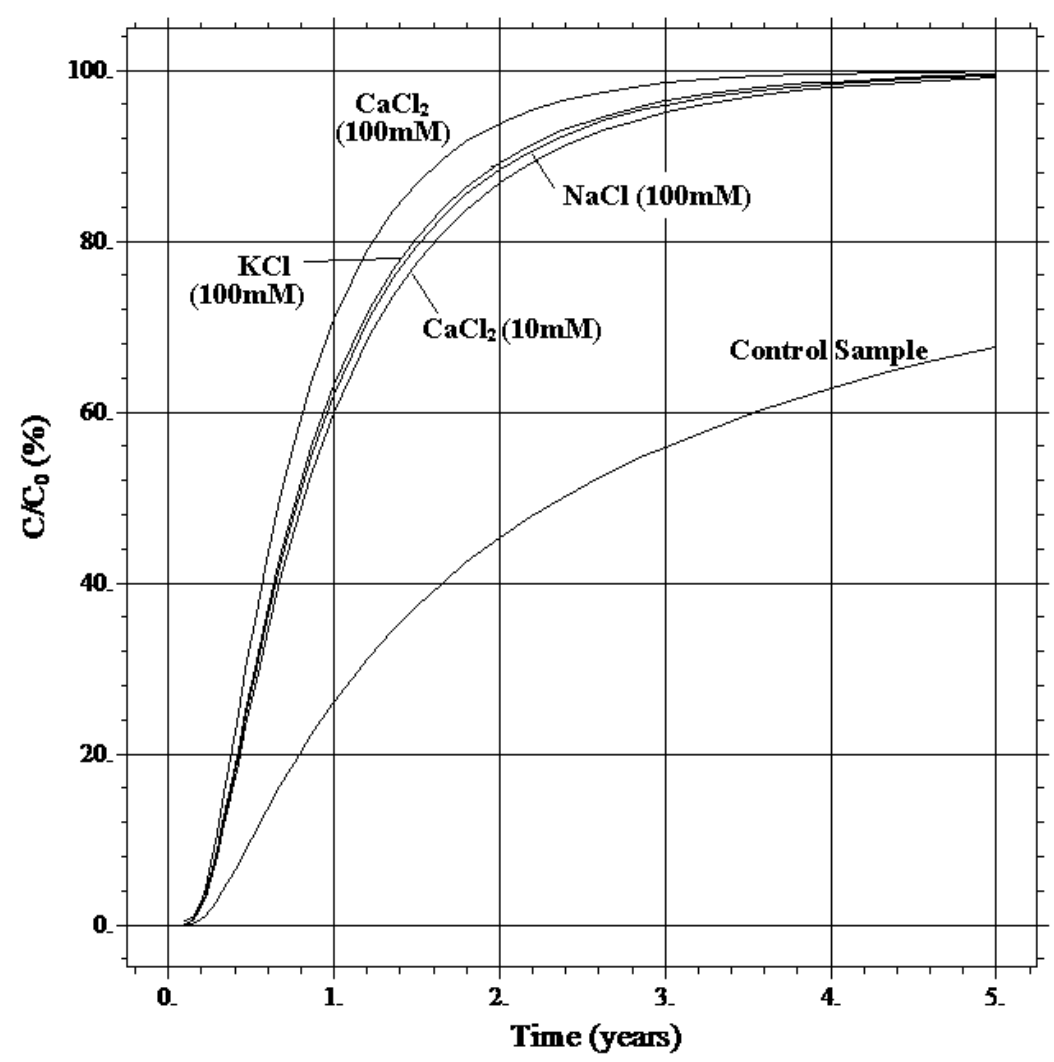

Fig. 7. Long-term effect with different permeant

Table 3. Input parameters and analysis results for bentonite barriers under hostile geo-chemical environment

\begin{tabular}{llllll}
\hline Case & $\mathrm{A}$ & $\mathrm{B}$ & $\mathrm{C}$ & $\mathrm{D}$ & $\mathrm{E}$ \\
\hline Permeant solution & $\mathrm{CaCl}_{2}$ & $\mathrm{CaCl}_{2}$ & $\mathrm{KCl}$ & $\mathrm{NaCl}$ & $\mathrm{Control}$ \\
Concentration $(\mathrm{mM})$ & 10 & 100 & 100 & 100 & Sample \\
Diffusion coefficient, $\mathrm{D}^{*}\left(\mathrm{~m}^{2} / \mathrm{s}\right)$ & $1 \times 10^{-9}$ & $1 \times 10^{-9}$ & $1 \times 10^{-9}$ & $1 \times 10^{-9}$ & $1 \times 10^{-9}$ \\
Saturated hydraulic conductivity, $\mathrm{k}_{\text {sat }}(\mathrm{m} / \mathrm{s})$ & $8.6 \times 10^{-11}$ & $1.1 \times 10^{-6}$ & $5.1 \times 10^{-11}$ & $4.4 \times 10^{-11}$ & $1.0 \times 10^{-12}$ \\
Break through Time (days) & 5.8 & 3.5 & 4.8 & 5 & 20 \\
Arriving Time for 50\% of concentration (years) & 0.84 & 0.62 & 0.71 & 0.73 & 2.5 \\
\hline
\end{tabular}

Figures 6 and 7 show an output that result from an effect of hydrating liquid on the hydraulic resistivity of bentonite berries. The completion of the break through took 20 days for the control sample. In comparison with the samples permeated by a chemical solution, the break through time have been reduced to circa 3 to 5 folds. This phenomena is most prevail in the strong $(100 \mathrm{mM})$ $\mathrm{CaCl}_{2}$ solution. It is also observed that the relative concentration versus time at the exit geological layer for samples permeated by chemical solution is much higher than the control sample. A more rapid concentration migration of the contaminant was generated within circa 4 to 5 years' time.

\section{Conclusion}

Achieving an understanding of the scientific basis to contaminant transport is essential to improve long term prediction of the leachate migration characteristic in engineered landfill design. Based upon the simulated model on hydraulic performance, clarification in model uncertainties as well as unfavorable defection due to poor construction in $\mathrm{CC}$ barriers; $\mathrm{PB}$ barriers is apparently substitutable for the conventional $\mathrm{CC}$ barriers. Factor affecting the performance of PB barriers have been critically presented and the effects have been illustrated through the modelling. Attention must be drawn to the deficiencies experienced in adopting PB barriers particularly when optimal prehydration state is not always accomplished. Design Engineer must not overlooked the desiccation cracking effect due drying process that occurs when barriers is isolated from ground water/subjected to freeze thaw effects/cation exchanged within bentonite. This phenomenal demonstrated a significantly resulted of much higher hydraulic flow through the barriers emphasized. 


\section{Acknowledgement}

The authors gratefully acknowledge the cited authors for the valuable information available in print in the public domain for the advancement and dissemination of the knowledge.

\section{Funding Information}

This work was supported by the INTI Research Grant (INT-FOSTEM-03-02-2014).

\section{Author's Contributions}

Authors jointly worked on deriving the results, writing and approved the final manuscript.

\section{Ethics}

The authors declare no conflict of interest.

\section{References}

Benson, C. and S. Meer, 2009. Relative abundance of monovalent and divalent cations and the impact of desiccation on geosynthetic clay liners. J. Geotech. Geoenviron. Eng., 135: 349-358. DOI: 10.1061/(ASCE)1090-0241(2009)135:3(349)

Benson, C., A. Oren and W. Gates, 2010. Hydraulic conductivity of two geosynthetic clay liners permeated with a hyperalkaline solution. J. Geotextiles Geomembranes, 28: 206-218. DOI: $10.1016 /$ j.geotexmem.2009.10.002

Bourg, I.C., G. Sposito and A.C.M. Bourg, 2007. Modeling cation diffusion in compacted watersaturated sodium bentonite at low ionic strength. Environ. Sci. Technol., 41: 8118-8122.

DOI: $10.1021 /$ es0717212

Bradshaw, S., C. Benson and J. Scalia, 2013. Hydration and cation exchange during subgrade hydration and effect on hydraulic conductivity of geosynthetic clay liners. J. Geotech. Geoenviron. Eng., 139: 526-538.

DOI: 10.1061/(ASCE)GT.1943-5606.0000793

Brown, L.C. and C.D. Shackelford, 2007. Hydraulic conductivity of a geosynthetic clay liner to a simulated animal waste solution. Trans. Am. Society Agric. Biol. Eng., 50: 831-841.

Cortazar, A.L.G. and I.D. Monzon, 2007. MODUELO 2: A new version of an integrated simulation model for municipal solid waste landfills. Environ. Model. Software, 22: 59-72.

DOI: $10.1016 /$ j.envsoft.2005.11.003

Egglofstein, T., 1997. Ion exchange in Geosynthetic Clay Liners. Industrial Fabrics Association International, St Paul USA.
Egloffstein, T.A., 2001. Natural bentonites-influence of the ion exchange and partial desiccation on permeability and self-healing capacity of bentonites used in GCLs. Geotextiles Geomembranes, 19: 427-444. DOI: $10.1016 / \mathrm{S} 0266-1144(01) 00017-6$

El-Fadel, M., A. Findikakis and J. Leckie, 1997. Modeling leachate generation and transport in solid waste landfills. Environ. Technol., 18: 669-686. DOI: $10.1080 / 09593331808616586$

García-Gutiérrez, M., J.L. Cormenzana, T. Missana and M. Mingarro, 2004. Diffusion coefficients and accessible porosity for $\mathrm{HTO}$ and $36 \mathrm{Cl}$ in compacted FEBEX bentonite. Applied Clay Sci., 26: 65-73. DOI: $10.1016 /$ j.clay.2003.09.012

Guyonnet, D., E. Gaucher, H. Gaboriau, C.H. Pons and C. Clinard et al., 2005. Geosynthetic clay liner interaction with leachate: Correlation between permeability, microstructure and surface chemistry. J. Geotech. Geoenviron. Eng., 131: 740-749. DOI: 10.1061/(ASCE)1090-0241(2005)131:6(740)

He, J., Y. Wang, Y. Li and X. Ruan, 2015. Effects of leachate infiltration and desiccation cracks on hydraulic conductivity of compacted clay. Water Sci. Eng., 8: 151-157. DOI: $10.1016 /$ j.wse. 2015.04 .004

Hewitt, P.J. and L.K. Philip, 1999. Problems of clay desiccation in composite lining systems. Eng. Geol., 53: $107-113$

DOI: $10.1016 / \mathrm{S} 0013-7952(99) 00023-\mathrm{X}$

Hosney, M.S. and R.K. Rowe, 2013. Changes in Geosynthetic Clay Liner (GCL) properties after 2 years in a cover over arsenic-rich tailings. Canadian Geotech. J., 50: 326-342. DOI: 10.1139/cgj-2012-0367

Iversen, N. and B.B. Jørgensen, 1993. Diffusion coefficients of sulfate and methane in marine sediments: Influence of porosity. Geochim. Cosmochim. Acta, 57: 571-578. DOI: 10.1016/0016-7037(93)90368-7

Jo, H.Y., C.H. Benson and T.B. Edil, 2004. Hydraulic conductivity and cation exchange in nonprehydrated and prehydrated bentonite permeated with weak inorganic salt solutions. Clays Clay Minerals, 52: 661-679.

DOI: $10.1346 / C C M N .2004 .0520601$

Jo, H.Y., T. Katsumi, C.H. Benson and T.B. Edil, 2001. Hydraulic conductivity and swelling of nonprehydrated GCLs permeated with single-species salt solutions. J. Geotech. Geoenviron. Eng., 127: 557-567. DOI: 10.1061/(ASCE)1090-0241(2001)127:7(557)

Katsumi, T., H. Ishimori, A. Ogawa, K. Yoshikawa and K. Hanamoto et al., 2007. Hydraulic conductivity of nonprehydrated geosynthetic clay liners permeated with inorganic solutions and waste leachates. Soils Foundations, 47: 79-96. DOI: 10.3208/sandf.47.79 
Koerner, R., 1997. Designing with Geosynthetics. 4th Edn., Prentice-Hall, Inc., Englewood Cliffs, New Jersey, USA.

Kolstad, D.C., C.H. Benson and T.B. Edil, 2004. Hydraulic conductivity and swell of nonprehydrated geosynthetic clay liners permeated with multispecies inorganic solutions. J. Geotech. Geoenviron. Eng., 130: 1236-1249. DOI: 10.1061/(ASCE)10900241(2004)130:12(1236)

Lee, J.M. and C.D. Shackelford, 2005. Concentration dependency of the prehydration effect for a geosynthetic clay liner. Soils Foundations, 45: 27-41.

Liu, Y., A. Bouazza, W.P. Gates and R.K. Rowe, 2015. Hydraulic performance of geosynthetic clay liners to sulfuric acid solutions. Geotextiles Geomembranes, 43: 14-23. DOI: 10.1016/j.geotexmem.2014.11.004

Mategaonkar, M. and T.I. Eldho, 2012. Twodimensional contaminant transport modeling using meshfree Point Collocation Method (PCM). Eng. Analysis Boundary Elements, 36: 551-561. DOI: 10.1016/j.enganabound.2011.11.001

Mazzieri, F., G. Di Emidio, E. Fratalocchi, M. Di Sante and E. Pasqualini, 2013. Permeation of two GCLs with an acidic metal-rich synthetic leachate. Geotextiles Geomembranes, 40: 1-11. DOI: $10.1016 /$ j.geotexmem.2013.07.011

McNeal, B., W. Norvell and N. Coleman, 1966. Effect of solution composition on the swelling of extracted soil clays. Soil Sci. Society Am. Proceed., 30: 313-317. DOI: $10.2136 /$ sssaj 1966.03615995003000030008x

Mesri, G. and R.E. Olson, 1971. Mechanisms controlling the permeability of clays. Clays Clay Minerals, 19: 151-158. DOI: 10.1346/CCMN.1971.0190303

Petrov, R. and R. Rowe, 1997. Geosynthetic Clay Liner (GCL)-chemical compatibility by hydraulic conductivity testing and factors impacting its performance. Canadian Geotech. J., 34: 863-885. DOI: $10.1139 / \mathrm{t} 97-055$

Rowe, R.K. and A. Verge, 2013. Prediction of geosynthetic clay liner desiccation in low stress applications. Geosynthetics Int., 20: 301-315. DOI: 10.1680/gein.13.00019

Ruhl, J. and D. Daniel, 1997. Geosynthetic clay liners permeated with chemical solutions and leachates. J. Geotech. Geoenviron. Eng., 123: 369-381. DOI: 10.1061/(ASCE)1090-0241(1997)123:4(369)

Scalia, J. and C.H. Benson, 2011. Hydraulic conductivity of geosynthetic clay liners exhumed from landfill final covers with composite barriers. J. Geotech. Geoenviron. Eng., 137: 1-13.

DOI: 10.1061/(ASCE)GT.1943-5606.0000407
Scalia, J., C. Benson, G. Bohnhoff, T. Edil and C. Shackelford, 2014. Long-term hydraulic conductivity of a bentonite-polymer composite permeated with aggressive inorganic solutions. J. Geotech. Geoenviron. Eng., 140: 04013025. DOI: 10.1061/(ASCE)GT.1943-5606.0001040

Shackelford, C.D. and D.E. Daniel, 1991a. Diffusion in saturated soil: Background. J. Geotech. Eng., 117: 467-484. DOI: $10.1061 /($ ASCE)07339410(1991)117:3(467)

Shackelford, C.D. and D.E. Daniel, 1991b. Diffusion in saturated soil. II: Results for compacted clay. J. Geotech. Eng., 117: 485-506. DOI: 10.1061/(ASCE)0733-9410(1991)117:3(485)

Shackelford, C.D. and K.M. Sample-Lord, 2014. Hydraulic Conductivity and Compatibility of Bentonite for Hydraulic Containment Applications. In: Principles and Practices in Geotechnical Engineering, Garlanger, J., M. Hussein and M. Iskander (Eds.), ASCE, Reston, VA.

Shackelford, C.D., C. Benson, T. Katsumi, T. Edil and L. Lin, 2000. Evaluating the hydraulic conductivity of GCLs permeated with non-standard liquids. Geotextiles Geomembranes, 18: 133-161. DOI: 10.1016/S0266-1144(99)00024-2

US EPA, 1993. Solid Waste Disposal Facility Criteria: Technical Manual. 1st Edn., US EPA, Washington, DC, pp: 349.

Vasko, S., H. Jo, C. Benson, T. Edil and T. Katsumi, 2001. Hydraulic conductivity of partially prehydratedgeosynthetic clay liners permeated with aqueous calcium chloride solutions. Proceedings of Geosynthetics Industrial Fabrics Association International, (FAI' 01), St. Paul, Minnesota, USA, pp: 685-699.

Wijeyesekera, D.C., 2003. Cation exchange capacity and swelling characteristics of geosynthetic clay liners. Proceedings of the International Conference on Problematic Soils, (CPS' 03), Nottingham, UK, pp: 553-561.

Wijeyesekera, D.C., E.W.K. Loh, F.D. Siti, A.J.M.S. Lim and A.B. Zainorabidin et al., 2012. Sustainability study of the application of geosynthetic clay liners in hostile and aggressive environments. OIDA Int. J. Sustainable Develop., 5: 81-96.

Zhu, C.M., W.M. Ye, Y.G. Chen, B. Chen and Y.J. Cui, 2013. Influence of salt solutions on the swelling pressure and hydraulic conductivity of compacted GMZ01 bentonite. Eng. Geol., 166: 74-80.

DOI: 10.1016/j.enggeo.2013.09.001 